\title{
Cross tolerance in beet armyworm: long-term selection by cadmium broadens tolerance to other stressors
}

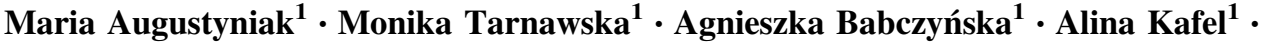 \\ Agnieszka Zawisza-Raszka ${ }^{1}$ - Bogumiła Adamek ${ }^{1}$ • Anna Płachetka-Bożek ${ }^{1}$
}

Accepted: 25 September 2017 / Published online: 23 October 2017

(C) The Author(s) 2017. This article is an open access publication

\begin{abstract}
Long lasting exposure of animals to stressing factor may lead to the selection of population able to cope with the stressor at lower cost than unexposed individuals. The aim of this study was to assess whether 130generational selection of a beet armyworm to cadmium in food might have induced tolerance also to other stressors. The potential tolerance was assessed by means of unspecific stress markers: HSP70 concentration, DNA damage level, and energy budget indices in L5 larval instars of beet armyworm. The animals originated from Cd-exposed and control strains exposed additionally in a short-term experiment to high/low temperature or pesticide—spinosad. The application of the additional stressors caused, in general, an increase in the levels of studied parameters, in a straindependent manner. The most significant increase was found in HSP70 level in the individuals from the Cd-strain exposed to various spinosad concentration. Therefore, multigenerational contact with cadmium caused several changes that enable the insect to survive under a chronic stress, preparing the organism to the contact with an additional, new stressor. This relationship may be described as a sort of cross tolerance. This may, possibly, increase the probability of population survivorship and, at the same time, decrease the efficiency of pesticide-based plant protection efforts.
\end{abstract}

Keywords Spodoptera exigua $\cdot$ Cadmium $\cdot \mathrm{HSP70} \cdot$ ATP content and ADP/ATP ratio $\cdot$ DNA damage

Maria Augustyniak

maria.augustyniak@us.edu.pl

1 Department of Animal Physiology and Ecotoxicology, University of Silesia in Katowice, Bankowa 9, Katowice, PL 40-007, Poland

\section{Introduction}

Long lasting exposure of animals to a particular stressor may lead to the selection of individuals which cope better with this, or perhaps also other, stressors. The phenomena like these are universal and may be observed in various regions in the world. The limitation of protein synthesis, suggesting the necessity to save energy reserves, have been noticed among invertebrates. The grasshoppers Chorthippus brunneus, from industrially polluted with heavy metals areas in Poland can be a good example. In the grasshoppers exposed to dimethoate different metabolic reactions were found in comparison to the populations inhabiting unpolluted sites (Augustyniak et al. 2005). In insects from polluted areas acetylcholinesterase (AChE), glutathione peroxidase (GPx), and superoxide dismutase (SD) activity was significantly lower than in insects from the reference site. Unlike this, carboxylesterase (CarE) and glutathione reductase (GR) activity did not change after pesticide application (Augustyniak et al. 2005). Similarly, in Chrysolina pardalina, a leaf beetle living on nickel accumulating plants in South Africa, after a single dimethoate application, AChE activity was diminished while GR activity remained unchanged (Augustyniak et al. 2007).

Insects selected in a laboratory for many generations under a specific stress factor can serve as a good, simplified model which can explain processes existing in the environment. This phenomenon is of particular and practical importance in case of insect species usually recognized as dangerous, highly expansive crop pests, e.g., Spodoptera exigua (Zheng et al. 2000). Acquisition of resistance toward specific toxin may serve as "new equipment" toward another one, e.g., pesticide.

Investigating reactions of animals, including selected ones, to stressing factors is crucial to choose universal, 
sensitive and acknowledged stress markers. Among the markers that fulfill the requirements there are: heat shock proteins-reflecting the dynamics of protein metabolism in an organism; level of DNA damage-describing the threat for molecules that are strategic for survival of an organism; ATP level and ADP/ATP ratio-indicating the pool of energy of an animal exposed to stress.

Heat shock proteins (HSP) initially have been regarded as taking part in defensive reactions to thermal stress. Further studies have shown that their expression can vary also in response to many other stressing factors (Eckwert and Köhler 1997; Pyza et al. 1997; Köhler et al. 1999; Knigge and Köhler 2000; Köhler et al. 2000; KarounaRenier and Zehr 2003; Arts et al. 2004; Haap and Köhler 2009; Jiang et al. 2012; Haap et al. 2016). There are even opinions that all known stressors may induce HSP expression (Feder and Hofmann 1999). Recent studies have reported the information about the cloning of HSP70 and HSP90 genes of S. exiqua and presented the expression of the genes in various developmental stages in response to thermal stress (Jiang et al. 2012). Heat shock protein expression has also been widely studied in animals exposed to heavy metals. In laboratory studies, often using laboratory-bred animals, positive correlation between HSP70 expression and metal content in food (or soil/water) was found. The response appeared much more difficult when chronically exposed animals, e.g., living in polluted habitats, were considered. It has been stated, among others, that HSP70 expression level might depend on the kind and concentration of a metal as well as on the exposure duration. The reports like this have initiated considerations on the HSP expression/concentration as a potential mechanism for adaptation, either transgenerational or genetically preserved. In the case of the latter concept there are authors who discuss the changes in HSP concentration at the level of (micro)evolution and analyze it in relations to possible trade-off between HSP induction and other protective mechanisms as well as the general fitness of the organism (Feder and Hofmann 1999). Developmental stage, sex, nutritional status, age and, possibly, acquired tolerance may also be the source of variation in HSP expression (Eckwert and Köhler 1997; Pyza et al. 1997; Köhler et al. 1999; Knigge and Köhler 2000; Köhler et al. 2000; Karouna-Renier and Zehr 2003; Arts et al. 2004). The present study may contribute to the explanation of the mechanisms of increased tolerance of invertebrates to chronic vs. acute as well as single vs. joint xenobiotics, connected with HSP70 level.

The assessment of DNA stand breaks in the cells seems to be a good marker since it can give information on the genotoxic potential of the habitat (Rojas et al. 1999; Dhawan et al. 2009). The information is valuable since the effects of genotoxic substances (DNA damage) are detectable at a very early stage, before disadvantageous consequences of this damage appear (Jha 2008). Apart from the detection of DNA damage resulting from chemical compounds released to the environment, the comet assay may, directly, ease the concluding about possible adaptations of an animal to the living in a polluted environment in a constant, multigenerational contact with a xenobiotic.

Possible adaptation is connected with the management of energy reserves and energy allocation towards repairing processes. For the animals under a constant pressure of toxic factors the realization of the repairing of the damage as well as the synthesis of new molecules to replace the damaged ones is a serious challenge that requires a compromise between the survival and reproduction (Calow and Sibly 1990; Jha 2008). In such grasp, a successful elimination of DNA damages, although it is a priority of an organism, may not always be realized in the highest efficiency. When an organism has a short lifespan, their main aim can be an energy investment into reproduction at the expense of the quality and length of the mother life.

For the assessment of DNA damage a comet assay (SCGE-Single Cell Gel Electrophoresis) seems to be efficient method. It enables the investigator both to detect the DNA (single and double-strand) breaks, caused by various mutagenic and toxic factors and to assess the repairing potential (Rojas et al. 1999; Collins 2009; Decordier et al. 2010; Collins 2014; Augustyniak et al. 2016a). Such metals as $\mathrm{Cu}, \mathrm{Pb}, \mathrm{Ni}, \mathrm{Cd}, \mathrm{Co}, \mathrm{Zn}$ can be found among the substances that were studied and analyzed by means of the comet assay to check whether they can generate breaks of DNA strands (Mitchelmore and Chipman 1998; Rojas et al. 1999; Mourón et al. 2001; Woźniak and Błasiak 2002; Augustyniak et al. 2016a; Augustyniak et al. 2016b).

Knowing the concentration of adenine nucleotides in the cells it is possible to calculate ADP/ATP ratio. This index informs about a general status of the cells and about the correlations between the anabolic and catabolic processes rates. The value of the index depends on such processes as proliferation, apoptosis and necrosis (Richter et al. 1996; Bradbury et al. 2000). The depletion of ATP in the cell will result in the increase in ADP/ATP ratio and will indicate the possibility of apoptotic or necrotic processes in animal tissues. In the opposite, if ATP pool is high, the ratio will be low, what will suggest that proliferation processes prevail and general condition of an animal is good (Sokolova et al. 2005; Babczyńska et al. 2011).

Since metals may significantly influence the ADP/ATP ratio, the parameter is used as a biomarker of the contact with toxic elements of this group. For example, cadmium sublethal exposure had significant effects on tissue energy status in the eastern oyster. Lower mitochondrial phosphorylation rate and proton leak as well as higher levels of steady-state ADP were observed after metal treatment 
(Sokolova et al. 2005). Another example can be found in the report of the studies on spiders Agelena labyrinthica collected from variously polluted habitats and exposed, under laboratory conditions, to cadmium and copper demonstrated that spiders exposed to metals had a significantly higher ADP/ATP ratio than the individuals from control groups (Babczyńska et al. 2011).

We assessed the level of the four sensitive stress markers described above (HSP70, DNA damage, ATP concentration, ADP/ATP ratio) in the insects from the cadmium and control strains and additionally exposed in an short test (5 days) to suboptimal temperature or pesticide - spinosad. The present study was conducted on Spodoptera exigua laboratory strain, bred for over 10 years in permanent contact with sublethal Cd concentration $\left(44 \mu \mathrm{g} \mathrm{Cd} \mathrm{g}^{-1}\right.$ dry weigh of food). We may suppose that insects from this strain can react to additional stressing factors in a different way than control ones (Kafel et al. 2012a; Kafel et al. 2012b; Augustyniak et al. 2016b).

The main aim of the study was to check if long-lasting, multigenerational contact with cadmium influences the ability of $S$. exigua to cope with additional stress factors.

\section{Materials and methods}

\section{Spodoptera exigua}

The individuals of beet armyworm (Spodoptera exigua) have been reared in Department of Animal Physiology and Ecotoxicology, Katowice, Poland since 1999. The unique cadmium strain, in which insects are continuously fed with cadmium-contaminated diet $(44 \mu \mathrm{g} \mathrm{Cd}$ per g of dry mass of food) was set up in 2005, and is kept till now. During this period over 130 generations underwent selection toward cadmium resistance.

Larvae and pupae were maintained in Petri dishes, whereas adults were kept in plastic cages of $2.5 \mathrm{~L}$ volume with unlimited access to water with honey $(10 \% \mathrm{v} / \mathrm{v})$. Larvae were fed ad libitum with an artificial diet containing: agar, water, wheat germ, casein, sucrose, yeast powder, formaldehyde, Wesson salt mixture, Vanderzant vitamin mixture, streptomycin sulfate, and methyl phydroxybenzoate. The temperature in the breeding room was $25 \pm 1{ }^{\circ} \mathrm{C}$, and light:dark cycle was $16: 8 \mathrm{~h}$.

The measurements were conducted on the 5th instar of $S$. exigua from control (C) and cadmium (Cd) strains. Newly emerged 4th instar of insects from both strains were subjected to different temperature conditions: $20,25,30^{\circ} \mathrm{C}$ (groups $\mathrm{t} 20$, t25, and $\mathrm{t} 30$, respectively) or spinosad: 0.2 , 0.02 and $0.002 \mathrm{mg} / \mathrm{kg}$ dry weight of the diet (groups s1, s2, s3, respectively). Spinosad concentrations were chosen according to previous pilot experiments. The highest spinosad concentration was established as the one that caused $50 \%$ mortality in both strains. The temperaturegroups were placed in an insect growth chamber to achieve and control desirable temperature. After short-term exposition (5 days), when the insects reached the 5 th instar, the individuals were slightly anaesthetized on ice, prepared for the measurements according to specific protocols for each marker, and HSP70 concentration, DNA damage level, ATP concentration as well as ADP/ATP ratio were measured according to standardized procedures. Insects from the control group maintained at $25^{\circ} \mathrm{C}$ (standard temperature condition in the stock population) served as the reference group.

\section{HSP70 level detection}

HSP content was determined by indirect ELISA protocol (Pyza et al. 1997), using primary and secondary antibody purchased in Sigma-Aldrich, USA.

The 5th instar larvae were slightly anaesthetized on ice and homogenized at $4{ }^{\circ} \mathrm{C}$ in phosphate buffer $(0.05 \mathrm{M}$, pH 7.4). Homogenates were then centrifuged at $15,000 \times g$ for $10 \mathrm{~min}$ at $4{ }^{\circ} \mathrm{C}$. The protein concentration in supernatants was measured according to Bradford (1976) with the use of bovine serum albumin (BSA, protein content $>95 \%$, Fluka) as the standard.

A microtiter plates were coated with samples that contained $100 \mu \mathrm{g}$ of protein. Strictly defined protein concentration for each of sample was adjusted by diluting supernatants with an appropriate amount of a phosphate buffer with protease inhibitors and antioxidative factors $(\mathrm{pH}$ 7.4; PMSF, $\mathrm{NaN}_{3}$, mercaptoethanol). After incubation (16 h at $4{ }^{\circ} \mathrm{C}$ ) the supernatants were removed and all wells were washed $(3 \times 10 \mathrm{~min})$ with phosphate buffer with Tween $(0.1 \mathrm{M} ; \mathrm{pH}$ 7.4). Next, the samples were blocked by $1 \%$ BSA (at $37^{\circ} \mathrm{C}$ for $1 \mathrm{~h}$ ) diluted in a phosphate buffer with additives, and again washed $(3 \times 10 \mathrm{~min})$ with the same phosphate buffer, as previously. The samples were then incubated (at $37^{\circ} \mathrm{C}$ for $2.5 \mathrm{~h}$ ) with the primary antibody against HSP70 (Monoclonal Anti-Heat Shock Protein 70 produced in mouse, Sigma-Aldrich, USA; dilution: 1:1000). After washing $(3 \times 10 \mathrm{~min})$ the samples were incubated at $37^{\circ} \mathrm{C}$ for $2 \mathrm{~h}$ with the secondary antibody conjugated with alkaline phosphatase (Anti-Mouse IgG - Alkaline Phosphatase antibody produced in goat, Sigma-Aldrich, USA; dilution: 1:1000). Next the samples were washed again $(3 \times 10 \mathrm{~min})$, and incubated with a phosphatase substrate solution pNPP (Sigma-Aldrich, USA) for the antibody complex visualization. The color intensity was measured in a microplate reader at a wavelength of $450 \mathrm{~nm}$ using UVVis spectrometer (TECAN Infinite M200, Austria). The concentration of HSP70 in the samples was calculated using 
a standard curve. All measurements were done in 7-10 replicates. Each sample was prepared using one individual.

\section{DNA damage assay}

DNA damage was measured by the comet assay according to the method described by Bilbao et al. (2002) with slight modifications implemented by Augustyniak et al. (2006). The genotoxic effect of pesticide and heat shock was measured in hemocytes of the 5th instar of $S$. exigua. Individuals were first slightly anesthetized on ice and then one proleg of a caterpillar was cut off. Then a drop of the hemolymph leaking from the incision $(20 \mu \mathrm{L})$ was immediately collected into Eppendorf tube that had previously been filled with $80 \mu \mathrm{L}$ of a phosphate buffer ( $\mathrm{pH}$ 7.4), and gently mixed. The cell suspension $(55 \mu \mathrm{L})$, kept on ice and in darkness, was mixed with $55 \mu \mathrm{L}$ of $1.5 \%$ low melting point agarose (LMPA; 1:1, v/v), and spread onto slides covered with $1 \%$ normal melting point agarose (NMPA). The third layer was made of $110 \mu \mathrm{l}$ of $1 \%$ LMPA. Then the slides were immersed in a lysis buffer $(2.5 \mathrm{M} \mathrm{NaCl}, 100$ mM EDTA, $10 \mathrm{mM}$ Tris, $0.25 \mathrm{M} \mathrm{NaOH}, 1 \%$ TritonX-100 and $10 \%$ dimethyl sulfoxide - DMSO, $\mathrm{pH} 10.0$ ) for $2 \mathrm{~h}$ at 4 ${ }^{\circ} \mathrm{C}$. The slides, after a gentle wash in ${ }_{\mathrm{d}} \mathrm{H}_{2} \mathrm{O}$, were placed in a horizontal gel electrophoresis unit in an electrophoretic buffer $(300 \mathrm{mM} \mathrm{NaOH}, 0.9 \mathrm{mM}$ Na2EDTA, $\mathrm{pH}>13)$ for $20 \mathrm{~min}$. Electrophoresis $(0.3 \mathrm{~A})$ were performed in a horizontal gel electrophoresis unit (Comet DNA set $2 \times 10$ with thermal stabilizer, Kucharczyk, Poland). After neutralization (0.4 M Tris-HCl; pH 7.4), the slides were fixed with methanol and dried overnight at room temperature. Before the analysis, slides were moistened with ${ }_{\mathrm{d}} \mathrm{H}_{2} \mathrm{O}$, dyed with $0.1 \%$ DAPI and visualized under a fluorescence microscope (Nikon Eclipse 80i with B\&W Video Camera SONY) with a Komet 5.5 image analysis system (Kinetic Imaging, Liverpool, UK). Each slide was prepared using one individual. Five individuals were tested in each experimental group. Tail DNA (TDNA, the percentage of DNA in the comet tail [\%]) was measured for 50 randomly selected nuclei on each slide. TDNA value depends directly on the level of DNA strand breaks. The higher level of DNA damage, the higher TDNA value.

\section{ATP concentration and ADP/ATP ratio}

To prepare the samples for the measurements, the individuals (whole bodies) were weighed and individually immersed in liquid nitrogen in order to immediately stop all the metabolic processes. Then frozen samples were homogenized in a porcelain mortar. Then the samples were deproteinized by the application of $1 \mathrm{M}$ perchloric acid in $\mathrm{v}$ : v 1:5 ratio. After centrifugation ( $5 \mathrm{~min}, 15,000 \mathrm{~g}$ ) the samples were neutralized by the addition of alkaline mixture of
$3 \mathrm{M} \mathrm{KOH}, 0.4 \mathrm{M}$ Tris, $3 \mathrm{M} \mathrm{KCl}$ (Napolitano and Shain 2005), to obtain $\mathrm{pH} 7.75$, optimal for luciferase activity. After the final centrifugation $(5 \mathrm{~min}, 8000 \mathrm{~g})$ the samples were used for luminometric measurements. For ATP concentration and ADP/ATP ratio BioVision ApoSENSORTM Cell Viability Assay Kit and ApoSENSORTM Assay Kit were used, respectively, according to the manufacturer's protocol.

\section{Statistical procedures}

For HSP70 level, ADP/ATP ratio and ATP content 7-10 individuals were tested in each experimental group. In order to check the normality of the data for all of the parameters, the Kolmogorov-Smirnov and Shapiro-Wilk tests were used. The homogeneity of the variances was tested using the Levene and Brown-Forsythe tests. Because the results of the HSP70 level, ADP/ATP ratio and ATP content fulfilled the criteria for normal distribution and variance homogeneity, parametric test (LSD test, ANOVA; $p<0.05$ ) was used to evaluate the significance of the differences among the experimental groups.

For the comet assay, five slides were analyzed in each experimental group. The means and medians were calculated for TDNA for each slide. The median values that were determined for each slide were used in further analyses. One-way ANOVA followed by Tukey post hoc test for multiple comparisons $(p<0.05)$ was used for the insects from each strain separately to check the differences in the damage level among experimental groups. Then means of the medians (of fifty nuclei that were measured on each slide) and standard deviation (SD) were presented in charts. Principal Component Analysis (PCA) was performed for evaluating the HSP70 level, ADP/ATP ratio, ATP content and DNA damage (expressed as Tail DNA). Statistical analysis was performed using Statistica 12.

\section{Results}

\section{Control strain vs. cadmium strain}

The analyses of stress parameters revealed differences between control and cadmium strains (Table 1). The level of stress protein was the parameter that mostly differentiated insects from both strains. In the case of this parameter no statistically significant differences between the insects from both strains in standard thermal conditions $\left(25^{\circ} \mathrm{C}\right)$ and in high temperature conditions $\left(30^{\circ} \mathrm{C}\right)$ were found. Level of DNA damage was the parameter that differentiated both strains at the lowest extent (Table 2). Only the exposure of insects to the lowest concentration of spinosad (s3 group) caused significant differences in DNA damage level in the 
insects from both strains (Table 1). ADP/ATP ratio differed significantly between the insects from both strains kept at low temperature $\left(20^{\circ} \mathrm{C}\right)$ or exposed to spinosad in the concentrations of $0.2,0.02 \mathrm{mg} / \mathrm{kg}$ dry weight of the diet (groups s1 and s2, respectively).

The lowest extent of differences in the levels of the studied parameters was found in the case of groups kept in standard conditions (t25 group). In this condition statistically significant differences between the insects form control and cadmium group were found only in the case of ATP concentration in the insect body (Table 1). Spinosad in the concentrations of 0.02 or $0.002 \mathrm{mg} / \mathrm{kg}$ dry weight of the diet (groups s2, and s3, respectively), was the factor that strongly differentiated the response of the insects from both strains.

\section{HSP70 level-analysis within each strain separately}

HSP70 level in the insects from the control strain, kept in standard temperature was equal to $0.031 / 100 \mu \mathrm{g}$ protein. This value should be treated as the reference one. Transfer of the insects for 5 days to the thermal conditions of 20 or $30{ }^{\circ} \mathrm{C}$ caused a significant increase or decrease in the level of stress protein, respectively.

Table 1 Summary of between-strain differences in the levels of studied parameters (ANOVA, LSD, $p<0.05$ )

\begin{tabular}{lllll}
\hline Control vs. cadmium strain & \multicolumn{5}{l}{ Dependent variables } \\
\cline { 2 - 5 } & HSP70 & TDNA & ADP/ATP & ATP \\
\hline $\mathrm{t} 20$ & $*$ & - & $*$ & - \\
$\mathrm{t} 25$ & - & - & - & $*$ \\
$\mathrm{t} 30$ & - & - & - & - \\
$\mathrm{s} 1$ & $*$ & - & $*$ & - \\
$\mathrm{s} 2$ & $*$ & - & $*$ & $*$ \\
$\mathrm{~s} 3$ & $*$ & $*$ & - & $*$ \\
\hline
\end{tabular}

Abbreviation: asterisks indicate statistically significant differences of mean values of each parameter (dependent variable) between individuals from control and cadmium strain within an experimental group
The application of spinosad as a stressing factor did not cause any significant increase in HSP70 synthesis in insects from the control strain (Fig. 1a).

In the insects form $\mathrm{Cd}$ strain a strong increase in HSP70 synthesis in response to spinosad, irrespectively of its dose was found (Fig. 1b). Similarly as in insects from the control strain, also in insects from the cadmium strain, a significant difference in HSP70 concentration between the individuals kept at 20 and $30^{\circ} \mathrm{C}$ was found.

\section{Level of DNA damage-analysis within each strain separately}

The initial level of DNA damage in the $\mathrm{t} 25$ group of the insects from the control strain, characterized by the TDNA parameter, was equal to $8.41 \%$. Both stressing factors (low/ high temperature, spinosad) did not caused any significant changes in the level of DNA damage in the insects from the control strain in comparison to the reference group ( $t 25$ group). In this strain significant differences between insects exposed to high and low temperature (t30 and t20 groups) and between insects exposed to high temperature and spinosad in the highest concentration ( $\mathrm{t} 30$ and $\mathrm{s} 3$ groups) were found (Fig. 2a).

In the cadmium strain, the level of DNA damage in the reference group was as low as $7.43 \%$ and did not differ from the value found for the insects kept at low/high temperature. The level of DNA damage was significantly higher in s2 group in comparison with the remaining spinosadtreated groups as well as t25 and t30 groups (Fig. 2b).

\section{ADP/ATP ratio-analysis within each strain separately}

ADP/ATP ratio of the insects from the control strain did not change in response to stress caused by high/low temperature and was similar to the value calculated for the reference group ( $\mathrm{t} 25$; mean value: 0.74 ), while the application of pesticide caused a significant, dose-dependent increase in the value of this marker (Fig. 3a).

In the groups of insects from the cadmium strain no significant changes were found in the value of ADP/ATP
Table 2 Analysis of variance for HSP70 concentration, TDNA, ADP/ATP ratio and ATP content in the body of Spodoptera exigua from control and cadmium strain and exposed in an acute test to different temperature conditions: 20,25 , $30{ }^{\circ} \mathrm{C}$ or spinosad: $0.2,0.02$ and $0.002 \mathrm{mg} / \mathrm{kg}$ dry weight of the diet (with strain and treatment as categorical factors)

\begin{tabular}{|c|c|c|c|c|c|c|c|c|c|}
\hline \multirow[t]{2}{*}{ Source of variation } & \multirow[t]{2}{*}{ d.f. } & \multicolumn{2}{|c|}{ HSP70 } & \multicolumn{2}{|c|}{ TDNA } & \multicolumn{2}{|c|}{ ADP/ATP } & \multicolumn{2}{|l|}{ ATP } \\
\hline & & $F$ & $p$ & $F$ & $p$ & $F$ & $p$ & $F$ & $p$ \\
\hline Strain (1) & 1 & 19.08 & $<0.001$ & 0.78 & 0.382 & 0.32 & 0.576 & 0.86 & 0.359 \\
\hline Treatment (2) & 5 & 11.51 & $<0.001$ & 2.40 & 0.046 & 2.51 & 0.043 & 7.30 & $<0.001$ \\
\hline$(1) \times(2)$ & 5 & 17.46 & $<0.001$ & 2.03 & 0.086 & 5.57 & $<0.001$ & 8.15 & $<0.001$ \\
\hline
\end{tabular}



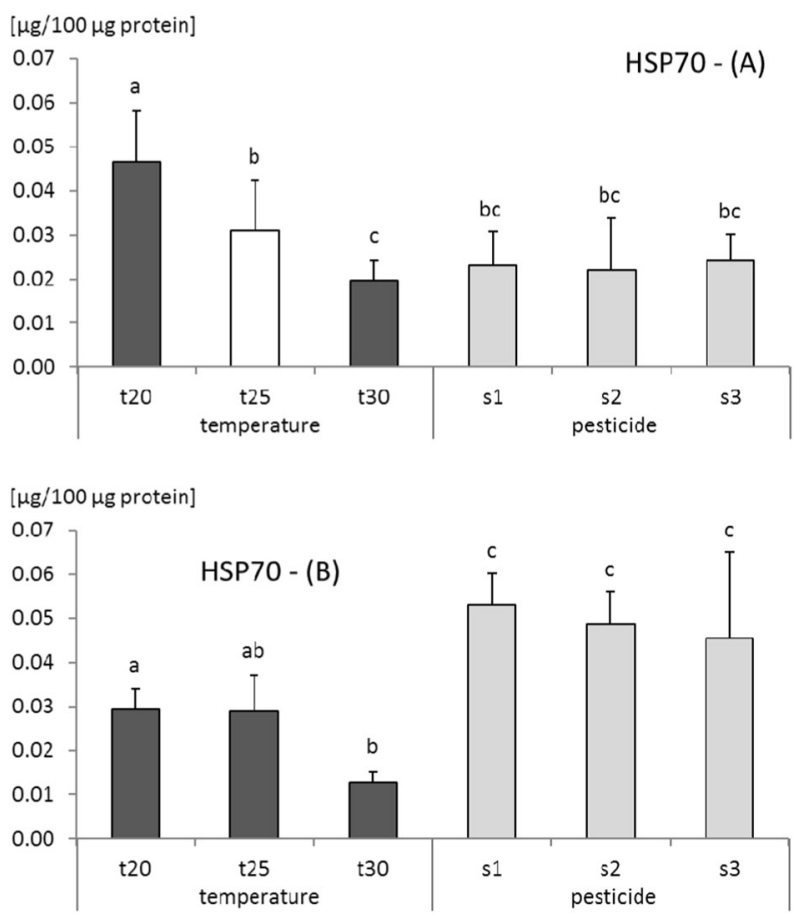

Fig. 1 HSP70 concentration (mean $\pm \mathrm{SD}$ ) in 5th instar of $S$. exigua from control $\mathbf{a}$ and cadmium strain $\mathbf{b}$, and exposed in an acute test to different temperature conditions: $20,25,30{ }^{\circ} \mathrm{C}$ (groups t20, t25 and t30, respectively) or spinosad: $0.2,0.02$ and $0.002 \mathrm{mg} / \mathrm{kg}$ dry weight of the diet (groups s1, s2, s3, respectively). The same letters indicate homogenous groups (ANOVA, LSD test; $p<0.05$ )

ratio in the groups: $\mathrm{t} 25, \mathrm{t} 30, \mathrm{~s} 1$ and $\mathrm{s} 2$. The exposure of the insects from $\mathrm{Cd}$ strain to low temperature or pesticide in the concentration of $0.002 \mathrm{mg} / \mathrm{kg}$ dry weight of the diet caused a significant increase of the value of this parameter. Both groups (t20 and s3) did not differ between each other (Fig. 3b).

\section{ATP concentration-analysis within each strain separately}

ATP concentration in the body of insects from the reference group was equal to $0.0022 \mathrm{mmol} / \mathrm{g}$ tissue and was significantly higher than the concentration found in the tissues of the insects exposed to low temperature. Also the application of spinosad in the concentration of $0.02 \mathrm{mg} / \mathrm{kg}$ dry weight of the diet caused a significant decrease in ATP concentration while spinosad in the lowest concentration $(0.002 \mathrm{mg} / \mathrm{kg}$ dry weight of the diet $)$ caused a significant increase in ATP concentration in comparison to the rest of the groups within the control strain (Fig. 4a).

An initial ATP level in the cadmium strain (t25 group) was low $(0.00039 \mathrm{mmol} / \mathrm{g})$. The stress caused by low/high temperature and by the contact with the highest concentration of spinosad did not cause any significant changes in ATP level in comparison to the reference group (t25
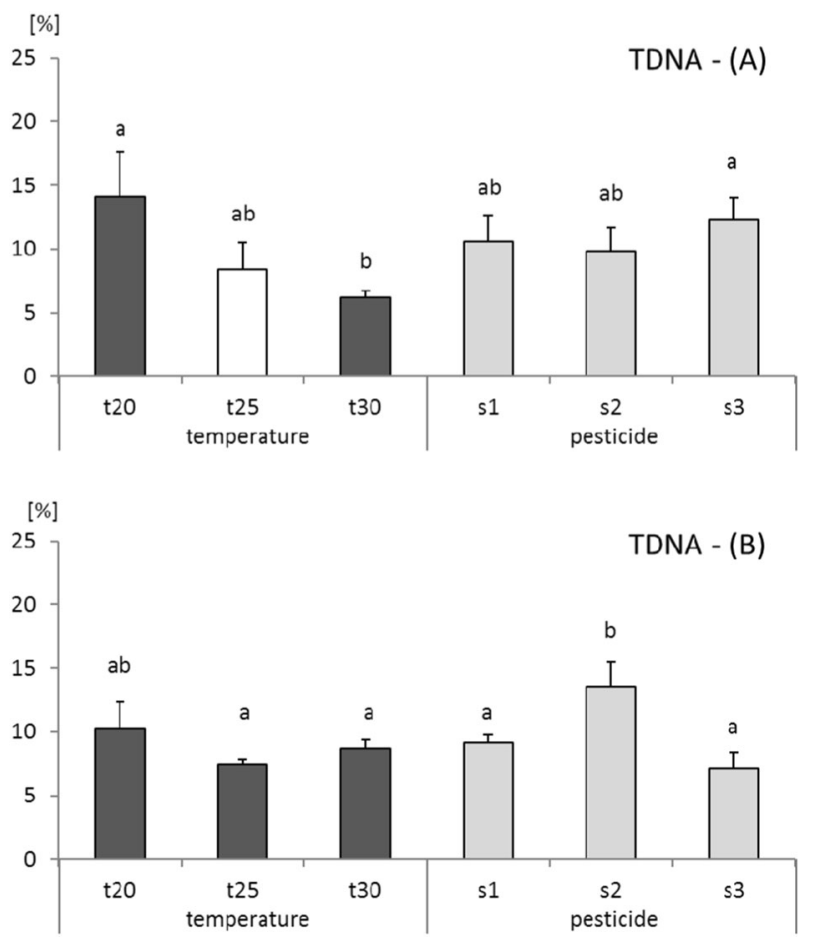

Fig. 2 Tail DNA (TDNA; mean $\pm \mathrm{SD}$ ) in 5th instar of $S$. exigua from control $\mathbf{a}$ and cadmium strain $\mathbf{b}$, and exposed in an acute test to different temperature conditions: $20,25,30^{\circ} \mathrm{C}$ (groups t20, $\mathrm{t} 25$ and $\mathrm{t} 30$, respectively) or spinosad: $0.2,0.02$ and $0.002 \mathrm{mg} / \mathrm{kg}$ dry weight of the diet (groups s1, s2, s3, respectively). Abbreviations: Bars - mean of the medians of fifty nuclei that were measured on each slide; the same letters indicate homogenous groups within each strain (ANOVA, Tukey test, $p<0.05$ )

group), while the application of spinosad in lower concentrations $(0.02$ and $0.002 \mathrm{mg} / \mathrm{kg}$ dry weight of the diet) caused an increase in ATP contents in the insect body. The highest stimulatory effect for the insects from the cadmium strain was caused by the medium spinosad concentration (s2 group). Average ATP concentration in the insects from this group was almost 10 times higher than in the 25 group (Fig. 4b).

\section{Results of Principal Component Analysis}

The results of PCA for control strain showed that two main components explained $72.2 \%$ of the total variation of parameter values. In the case of control strain the first component was associated with ADP/ATP ratio and ATP content. These two parameters were strongly correlated with each other. The second component was associated with HSP70 level in the insect tissues from the control strain (Fig. 5a). The results of PCA indicated that in cadmium strain, two main components explained $80.5 \%$ of the total variation of parameter values. The first component was associated with parameters: HSP70, TDNA, and ATP. The second component was associated with ADP/ATP ratio. In 

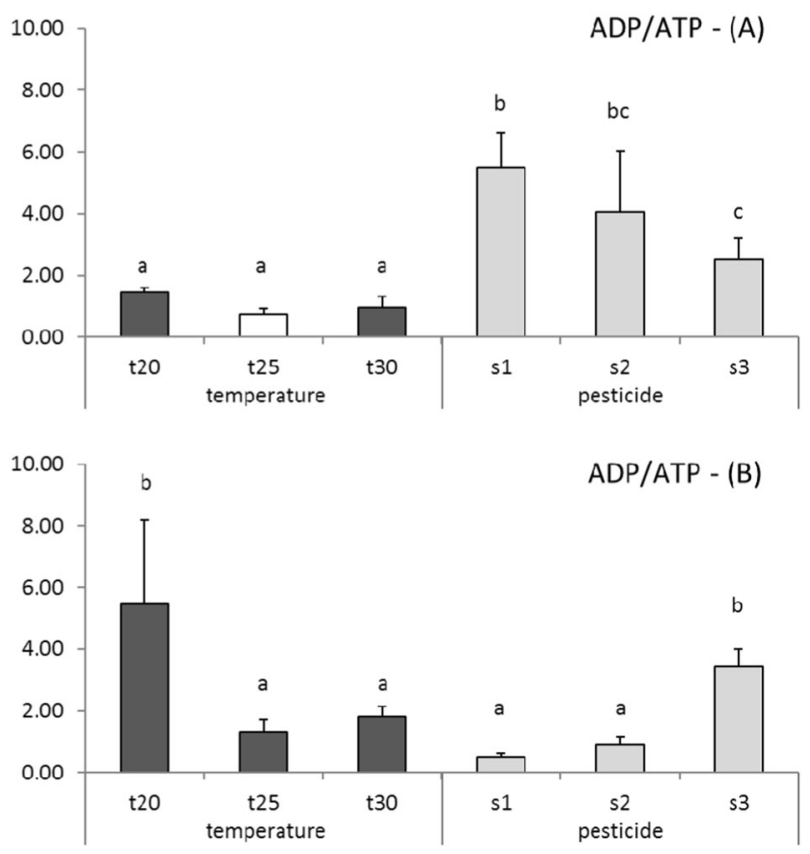

Fig. 3 ADP/ATP ratio (mean $\pm \mathrm{SD}$ ) in 5th instar of $S$. exigua from control $\mathbf{a}$ and cadmium strain $\mathbf{b}$, and exposed in an acute test to different temperature conditions: $20,25,30^{\circ} \mathrm{C}$ (groups t20, t25 and $\mathrm{t} 30$, respectively) or spinosad: $0.2,0.02$ and $0.002 \mathrm{mg} / \mathrm{kg}$ dry weight of the diet (groups s1, s2, s3, respectively). The same letters indicate homogenous groups (ANOVA, LSD test; $p<0.05$ )

the case of cadmium strain the level TDNA and ATP were correlated with each other (Fig. 5b).

\section{Discussion}

The results of this study demonstrate how the biomarkers may differ in two populations of the same species, if one of them has been exposed to constant contact with sublethal doses of a toxin-cadmium.

The phenomenon of pressure exerted by external factors, especially unfavorable ones, takes place in the natural environment, e.g in anthropogenically changed areas. Irrespectively of its basis, the changes in the protective mechanisms level enhance survivorship chance of a population under stressing conditions (Ho and Burggren 2010; Hendry et al. 2011; Feil and Fraga 2012). The experiment conducted on an unique isolated $\mathrm{Cd}$-selected population of $S$. exigua gave us the opportunity to observe the changes under controlled conditions. Similar investigations would never be possible in the case of field populations.

The comparisons of HSP70 contents in the body of $S$. exigua from both reference strains (temperature $25^{\circ} \mathrm{C}$ ) did not reveal any significant between-strain differences (Fig. 1). Therefore we might suppose that multigenerational
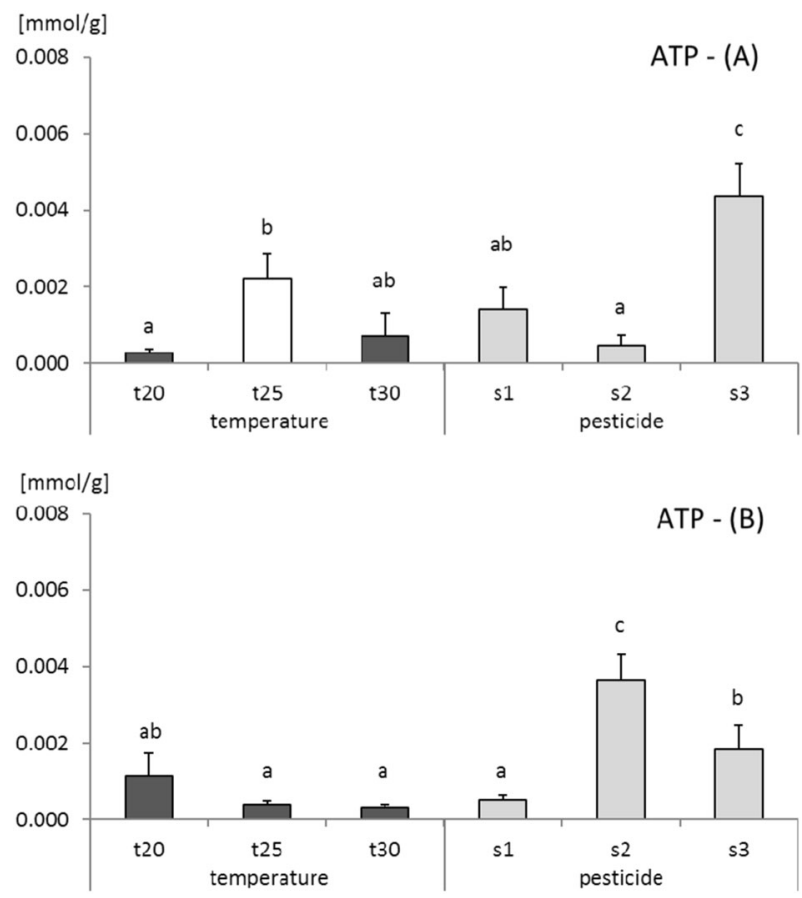

Fig. 4 ATP concentration (mean \pm SD) in 5th instar of $S$. exigua from control $\mathbf{a}$ and cadmium strain $\mathbf{b}$, and exposed in an acute test to different temperature conditions: $20,25,30^{\circ} \mathrm{C}$ (groups t20, $\mathrm{t} 25$ and $\mathrm{t} 30$, respectively) or spinosad: $0.2,0.02$ and $0.002 \mathrm{mg} / \mathrm{kg}$ dry weight of the diet (groups s1, s2, s3, respectively). The same letters indicate homogenous groups (ANOVA, LSD test; $p<0.05$ )

selection (lasting for over 130 generations) of S. exigua did not influence a constitutive level of HSP70, and the level of these proteins detected in this study should be regarded as optimal for the development of the insects from both strains. The between-strain differences in the level of stress proteins got visible in the response induced by additional stressors. The reaction to the changed temperature was similar in the insects from both strains from our culture (Table 1, Fig. 1). Jiang et al. (2012) showed that transcriptional expression of S. exiqua HSP70 is up-regulated under thermal stress. A significant increase in HSP70 expression was demonstrated for all larval stages after heat shock treatment for $1 \mathrm{~h}$ in the temperature of 43 and $45^{\circ} \mathrm{C}$. Translational expression of HSP70 (by means of Western blot) was correlated with HSP70 RNA expression (Jiang et al. 2012). It should be stressed that in our research a stressing temperatures in the insect rearing chamber $\left(20\right.$ and $\left.30^{\circ} \mathrm{C}\right)$ were different from the typical (reference) one $\left(25^{\circ} \mathrm{C}\right)$, however, they were still within the range of thermal conditions enabling the insect a proper ontogenesis. That is why the results obtained in this study should be interpreted in the context of the species physiology. In the temperature of $20^{\circ} \mathrm{C}$ the ontogenesis was prolonged, especially in the case of the insects from the control strain. This may mean that high HSP70 level in the t20 group, especially in the control strain, might have 
Fig. 5 Principal component analysis (PCA) of the measured parameters in S. exigua from control $\mathbf{a}$ and cadmium strain $\mathbf{b}$ exposed in the laboratory to natural (temperature) and anthropogenic (pesticide) stress factors
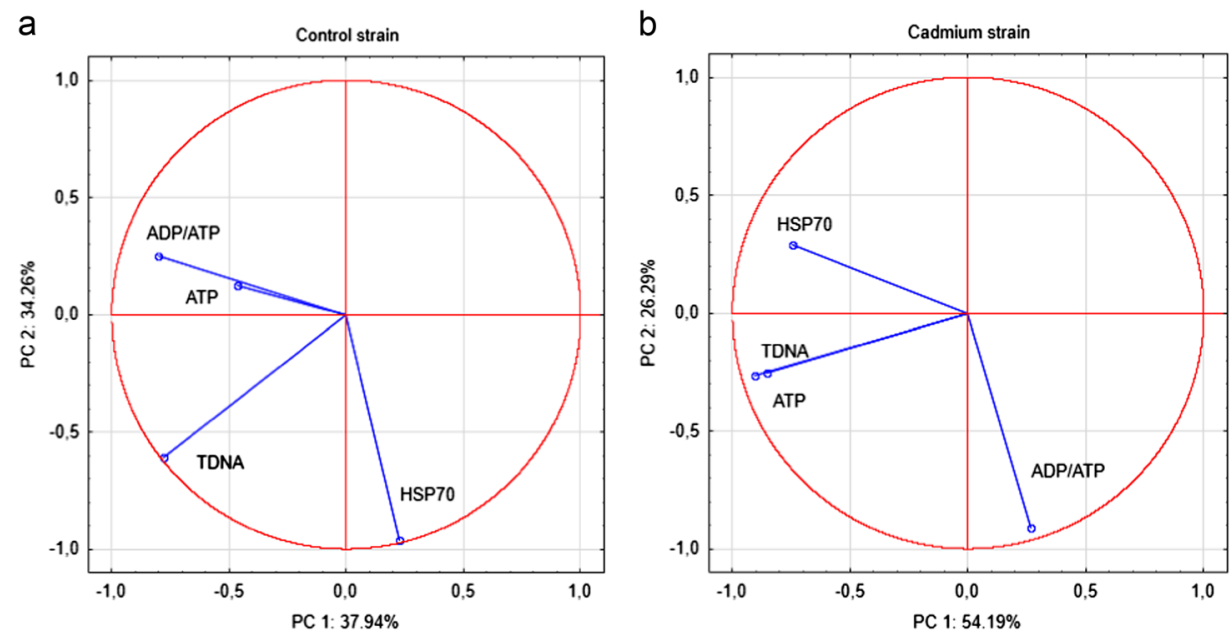

resulted from constant morphogenetic processes connected with natural synthesis of new proteins. In the temperature of $30{ }^{\circ} \mathrm{C}$ these phenomena might have completed what was reflected as the lower HSP70 level (Fig. 1). The confirmation to this explanation may be found also in the developmental table for $S$. exigua made by Karimi-Malati et al (2014) at various temperatures. The authors confirm that $25^{\circ} \mathrm{C}$ is optimal for $S$. exigua development, while the processes gets prolonged or shortened under, respectively, lower or higher thermal conditions. Increased metabolic processes rate in higher temperature exposure may also result in a kind of trade-off between the heat shock protein synthesis and growth expenditures. Moreover, the authors stress that $36^{\circ} \mathrm{C}$ appeared to be a real stressing temperature (no development at all) while the temperature of $33^{\circ} \mathrm{C}$ caused the strongest reduction of the development time (by, nearly, 2 times) (Karimi-Malati et al. 2014). Moreover, taking under consideration the fact that in the quoted experiment adult females reared under higher temperature conditions laid less eggs than the insects from the optimal temperature $\left(25^{\circ} \mathrm{C}\right)$, we may suppose that the exposure to higher temperature requires various energy trade-offs that, probably, start even at younger (larval) developmental stages and they may be revealed by the lower level of HSP70 in the insects reared under $30^{\circ} \mathrm{C}$.

The role of HSP70 in the development of metal tolerance and cross tolerance was also discussed. There are data suggesting that HSP70 level changed in relation to the exposure duration (Eckwert and Köhler 1997). In the studies conducted on two Daphnia magna clones which differed in $\mathrm{Cd}$ sensitivity and HSP70 level, it was demonstrated that high HSP70 level did not reassure the increase of tolerance to $\mathrm{Cd}$ and heat shock. The authors suggest that there must be a trade-off between the HSP70 and metallothionein (MT) which are induced to sequester and detoxify cadmium (Haap et al. 2016). On the other hand, in our study spinosad application caused a significant increase in HSP70 concentration in the body of the insects from the Cd-strain in comparison to the insects from the control strain. Enhanced synthesis of heat shock proteins is, in general, regarded as a protective mechanism against environmental stress (Multhoff et al. 2015; Sandbichler and Höckner 2016). However, the reports can be found presenting examples of adapted ecotypes of invertebrates, that are insensitive to pollutants, including cadmium, and, at the same time, they have low HSP concentration (Haap and Köhler 2009; Haap et al. 2016). In the case of our results, chronic exposure to toxicants lays an important role in the development of the tolerance (Haap and Köhler 2009; Haap et al. 2016).

Due to the general, broad protective properties of this group of proteins it may be expected that the inducibility of these proteins may be the basis for selection of the individuals that express higher tolerance to the inducing factor. This means that the individuals of this ability are promoted when a chronic toxic factor exerts a pressure to the population (Katsikatsou et al. 2011; Cantinha et al. 2017). Therefore, the mobilization of energy reserves for the prevention against the effects of toxic effects of spinosad by HSP70-triggered repair of damaged protein, may be regarded as an efficient protective mechanism in the insects from the cadmium strain, and may be interpreted as a sort of cross tolerance.

The comparison of the energy management by $S$. exigua from our culture (ADP/ATP ratio) demonstrates the range of the problem an animal must cope with under an additional stress conditions (Fig. 3). High value of ADP/ATP ratio found especially in the groups of insects exposed to spinosad in the control strain indicates concentrationdependent utilization of energy reserves and the enhancement of anabolic processes. In the cadmiun strain, in spite of an increase of HSP70 synthesis, no significant increase in 
ADP/ATP ratio in the groups exposed to spinosad in the highest and middle concentrations was observed. The initiation of defensive mechanisms may be connected with the increase of metabolic activity and energy consumption. During reproduction, heat exposure or other stress, when energy demand is high, the production of ATP could be insufficient and the animal could suffer from energy shortage. This may lead to the changes of the adenine nucleotide concentrations in the tissues. There are no many reports on the adenine nucleotides concentration in relation to environmental factors acing on living organisms (in contrast to cell lines). Among the few report there are the studies on spiders Agelena labyrinthica collected from variously polluted habitats and exposed, under laboratory conditions, to cadmium and copper. The results demonstrated that spiders from polluted sites and exposed to metals had a significantly (up to 9 times) higher ADP/ATP ratio than the individuals from control groups. It is worth mentioning that the level of ATP in all experimental groups was rather high and constant what may indicate efficient energy supplies in animals potentially adapted to environmental pressure (Babczyńska et al. 2011).

Summarizing, the results obtained in this study, together with the data on other invertebrates suggests that the insects from the cadmium strain are able to manage energy reserves in an efficient way in the conditions of an additional stress.

The level of DNA damage, measured by means of the comet assay is a widely used marker of exposure to stressing factors. It is a very sensitive parameter, however the result should be always interpreted in the context of the duration of the exposure to the specific stressor (Augustyniak et al. 2016b). In our previous studies we compared the rate of repair of DNA damage, induced artificially by an addition of $\mathrm{H}_{2} \mathrm{O}_{2}$ to the suspension of cells isolated from the body of $S$. exigua larvae. The results of these studies indicated that the insects from the cadmium strain are characterized by a higher potential to repair DNA damage.

Basing on this observation we are willing to consider the hypothesis that multigenerational exposure to cadmium may possibly contribute to the selection of insects that have a wider tolerance to oxidative stress (Augustyniak et al. 2016b). In the present study additional stressing factors: an anthropogenic one - spinosad and natural one - a temperature that is not optimal for the development did not caused any spectacular increase in the level of DNA damage. It should be remembered, however, that the duration of exposure was equal to 5 days. This period is sufficient for the synthesis of the necessary enzymatic apparatus responsible for the repair of such important molecules as DNA.

The results of this investigation enable us to suppose that multigenerational exposure to sublethal $\mathrm{Cd}$ doses led to the improvement of defensive mechanisms against an additional stressing factor. We are willing to express a supposition that long-lasting, multigenerational contact with cadmium caused several changes that enable the insect to survive under a chronic stress, preparing the organism to the contact with an additional, new stressor.

Long-lasting, multigenerational contact with cadmium caused several changes that enable the insect to survive under a chronic stress, preparing the organism to the contact with an additional, new stressor. Following the theory that the resistance is connected with lower energy allocation the cross tolerance may be indicated by the adenine nucleotide analyses. According to our results, ADP/ATP ratio in the control strain is very high (this means that denominator of the fraction is low and the numerator is high), so the ATP utilization seems intensive. This may mean that it is, among others, used for the elimination of the spinosad effect so ATP concentration is low (denominator) and resulting ADP concentration high (numerator). In contrast, in two high spinosad concentration groups s1 and s2, the disproportion between ATP and ADP concentrations is not that high, so the value of the ADP/ATP ratio is lower. This may indicate that the defense against spinosad does not require higher energy consumption (=increased tolerance). In this case it may be a cross tolerance since the phenomenon appeared in the Cd-selected strain.

Unfortunately, in the experiment like this, where we use phenotypic, not molecular, markers we do not dare suppose what may be the origin: genetic or epigenetic. At the level of the markers we have chosen we can not even conclude whether the increased tolerance is inheritable or whether it depends on phenotypic plasticity of the individuals. It may be also supposed that the bigger plasticity of the phenotype was the feature that was favored by the selection pressure. Possible changes at the genetic level might be identified by the molecular methods. However, to plan a reliable investigation and to search for the genes responsible for the increased tolerance, it is necessary to analyze phenotypic phenomena, to indicate the potential genes. Such physiological attempt was also proposed and justified by analogous studies on $\mathrm{Cd}$-sensitive and Cd-resistant populations of Chironomus riparius with the usage of cellular defensive mechanisms, oxidative stress and energy metabolism parameters (Perdosa et al. 2017). As in our study, the authors did not try to give any evidence for the origin of the tolerance. At present we are working on detailed elaboration of this issue. We already know that the insects from the cadmium strain have a modified gene for vitellogenin, the most important protein deposed in eggs. We do not know yet whether this modification may improve the utilization of the reserve material and increase the survivorship chance of the insects, including pest insects, selected towards the resistance to a given stressor. Our future investigations will probably enable us to find the response to this question. 
Author contributions M.A., A.K., M.T., and A.B. designed research. M.A., M.T., A.B., B.A., A.K., A.Z.-R., and A.P.-B. conducted experiments. M.A., M.T., A.B. analyzed data. M.A., A.B., M.T. wrote the manuscript. All authors read and approved the manuscript.

Funding This study was funded by National Science Centre, Poland (grant number DEC-2013/09/B/NZ9/01754).

\section{Compliance with ethical standards}

Conflict of interest The authors declare that they have no competing interests.

Ethical approval This article does not contain any studies with human participants performed by any of the authors. All applicable international, national, and/or institutional guidelines for the care and use of animals were followed.

Open Access This article is distributed under the terms of the Creative Commons Attribution 4.0 International License (http://crea tivecommons.org/licenses/by/4.0/), which permits unrestricted use, distribution, and reproduction in any medium, provided you give appropriate credit to the original author(s) and the source, provide a link to the Creative Commons license, and indicate if changes were made.

\section{References}

Arts M-J, Schill R, Knigge T et al. (2004) Stress proteins (hsp70, hsp60) induced in isopods and nematodes by field exposure to metals in gradient near Avonmouth, UK. Ecotoxicology 13:739-755

Augustyniak M, Babczyńska A, Migula P et al. (2005) Joint effects of dimethoate and heavy metals on metabolic responses in a grasshopper (Chorthippus brunneus) from a heavy metals pollution gradient. Comp Biochem Physiol C Toxicol Pharmacol 141:412-419. https://doi.org/10.1016/j.cbpc.2005.09.007

Augustyniak M, Gladysz M, Dziewięcka M (2016a) The Comet assay in insects - status, prospects and benefits for science. Rev Mutat Res 767:67-76. https://doi.org/10.1016/j.mrrev.2015.09.001

Augustyniak M, Juchimiuk J, Przybyłowicz WJ et al. (2006) Zincinduced DNA damage and the distribution of metals in the brain of grasshoppers by the comet assay and micro-PIXE. Comp Biochem Physiol C Toxicol Pharmacol 144:242-251. https://doi. org/10.1016/j.cbpc.2006.09.003

Augustyniak M, Migula P, Mesjasz-Przybyłowicz J et al. (2007) Short-term effects of dimethoate on metabolic responses in Chrysolina pardalina (Chrysomelidae) feeding on Berkheya coddii (Asteraceae), a hyper-accumulator of nickel. Environ Pollut 150:218-224. https://doi.org/10.1016/j.envpol.2007.01.018

Augustyniak M, Płachetka-Bożek A, Kafel A et al. (2016b) Phenotypic plasticity, epigenetic or genetic modifications in relation to the duration of $\mathrm{Cd}$-exposure within a microevolution time range in the beet armyworm. PLoS One 11:e0167371. https://doi.org/ 10.1371/journal.pone.0167371

Babczyńska A, Wilczek G, Wilczek P et al. (2011) Metallothioneins and energy budget indices in cadmium and copper exposed spiders Agelena labyrinthica in relation to their developmental stage, gender and origin. Comp Biochem Physiol 154:161-171
Bilbao C, Ferreiro JA, Comendador MA, Sierra LM (2002) Influence of mus201 and mus308 mutations of Drosophila melanogaster on the genotoxicity of model chemicals in somatic cells in vivo measured with the comet assay. Mutat Res Fundam Mol Mech Mutagen 503:11-19. https://doi.org/10.1016/S0027-5107(02) 00070-2

Bradbury DA, Simmons TD, Slater KJ, Crouch SPM (2000) Measurement of the ADP:ATP ratio in human leukaemic cell lines can be used as an indicator of cell viability, necrosis and apoptosis. J Immunol Methods 240:79-92. https://doi.org/10.1016/ S0022-1759(00)00178-2

Bradford M (1976) A rapid and sensitive method for the quantitation of microgram quantities of protein utilizing the principle of protein dye binding. Anal Biochem 72:248-254

Calow P, Sibly RM (1990) A physiological basis of population processes: ecotoxicological implications. Funct Ecol 4:283-288. https://doi.org/10.2307/2389587

Cantinha S, Borrely SI, Oguiura N et al. (2017) HSP70 expression in Biomphalaria glabrata snails exposed to cadmium. Ecotoxicol Environ Saf 140:18-23. https://doi.org/10.1016/j.ecoenv.2017. 02.026

Collins A (2009) Investigating oxidative DNA damage and its repair using the comet assay. Rev Mutat Res 681:24-32. https://doi.org/ 10.1016/j.mrrev.2007.10.002

Collins AR (2014) Measuring oxidative damage to DNA and its repair with the comet assay. BBA Gen Subj 1840:794-800. https://doi. org/10.1016/j.bbagen.2013.04.022

Decordier I, Loock KVande, Kirsch-Volders M (2010) Phenotyping for DNA repair capacity. Mutat Res 705:107-129. https://doi.org/ 10.1016/j.mrrev.2010.05.002

Dhawan A, Bajpayee M, Parmar D (2009) Comet assay: A reliable tool for the assessment of DNA damage in different models. Cell Biol Toxicol 25:5-32. https://doi.org/10.1007/s10565-0089072-z

Eckwert H, Köhler H-R (1997) The indicative value of the hsp70 stress response as a marker for metal effects in Oniscus asellus (Isopoda) field populations: variability between populations from metal-polluted and uncontaminated sites. Appl Soil Ecol 6:275-282

Feder ME, Hofmann GE (1999) Heat-shock proteins, molecular chaperones, and the stress response: Evolutionary and Ecological Physiology. Annu Rev Physiol 61:243-82

Feil R, Fraga MF (2012) Epigenetics and the environment: emerging patterns and implications. Nat Rev Genet 13:97-109. https://doi. org/10.1038/nrg3142

Haap T, Köhler H-R (2009) Cadmium tolerance in seven Daphnia magna clones is associated with reduced hsp70 baseline levels and induction. Aquat Toxicol 94:131-137. https://doi.org/10. 1016/j.aquatox.2009.06.006

Haap T, Schwarz S, Köhler H-R (2016) Metallothionein and Hsp70 trade-off against one another in Daphnia magna cross-tolerance to cadmium and heat stress. Aquat Toxicol 170:112-119. http://dx. doi.org/10.1016/j.aquatox.2015.11.008

Hendry AP, Kinnison MT, Heino M et al. (2011) Evolutionary principles and their practical application. Evol Appl 4:159-183. https://doi.org/10.1111/j.1752-4571.2010.00165.x

Ho DH, Burggren WW (2010) Epigenetics and transgenerational transfer: a physiological perspective. J Exp Biol 213:3-16. https://doi.org/10.1242/jeb.019752

Jha AN (2008) Ecotoxicological applications and significance of the comet assay. Mutagenesis 23:207-221. https://doi.org/10.1093/ mutage/gen014

Jiang X, Zhai H, Wang L et al. (2012) Cloning of the heat shock protein 90 and 70 genes from the beet armyworm, Spodoptera exigua, and expression characteristics in relation to thermal stress and development. Cell Stress Chaperon- 17:67-80 
Kafel A, Nowak A, Bembenek $\mathbf{J}$ et al. (2012a) The localisation of HSP70 and oxidative stress indices in heads of Spodoptera exigua larvae in a cadmium-exposed population. Ecotoxicol Environ Saf 78:22-27. https://doi.org/10.1016/j.ecoenv.2011.10.024

Kafel A, Zawisza-Raszka A, Szulińska E (2012b) Effects of multigenerational cadmium exposure of insects (Spodoptera exigua larvae) on anti-oxidant response in haemolymph and developmental parameters. Environ Pollut 162:8-14. https://doi.org/10. 1016/j.envpol.2011.09.034

Karimi-Malati A, Fathipour Y, Talebi AA, Bazoubandi M (2014) Life table parameters and survivorship of Spodoptera exigua (Lepidoptera: Noctuidae) at constant temperatures. Environ Entomol 43:795-803. http://dx.doi.org/10.1603/EN11272

Karouna-Renier N, Zehr J (2003) Short-term exposures to chronically toxic copper concentrations include HSP70 proteins in midge larvae (Chironomus tentans). Sci Total Environ 312:267-272

Katsikatsou M, Anestis A, Pörtner HO et al. (2011) Field studies on the relation between the accumulation of heavy metals and metabolic and HSR in the bearded horse mussel Modiolus barbatus. Comp Biochem Physiol Part C 153:133-140. https://doi. org/10.1016/j.cbpc.2010.10.001

Knigge T, Köhler H-R (2000) Lead impact on nutritions, energy reserves, respiration and stress protein (hsp70) level in Porcellio scaber (Isopoda) populations differently preconditioned in their habitats. Environ Pollut 108:209-217

Köhler H-R, Eckwert H, Triebskorn R, Bengtsson G (1999) Interaction between tolerance and $70 \mathrm{kDa}$ stress protein (hsp70) induction in collembolan populations exposed to long-term metal pollution. Appl Soil Ecol 11:43-52

Köhler H-R, Zanger M, Eckwert H, Einfeldt I (2000) Selection favours low hsp70 in chronically metal-stressed soil arthropods. J Evol Biol 13:569-582

Mitchelmore CL, Chipman JK (1998) DNA strand breakage in aquatic organisms and the potential value of the comet assay in environmental monitoring. Mutat Res Fundam Mol Mech Mutagen 399:135-147. https://doi.org/10.1016/S0027-5107(97) 00252-2
Mourón SA, Golijow CD, Dulout FN (2001) DNA damage by cadmium and arsenic salts assessed by the single cell gel electrophoresis assay. Mutat Res Genet Toxicol Environ Mutagen 498:47-55. https://doi.org/10.1016/S1383-5718(01)00266-2

Multhoff G, Pockley AG, Schmid TE, Schilling D (2015) The role of heat shock protein 70 (Hsp70) in radiation-induced immunomodulation. Cancer Lett 368:179-184. https://doi.org/10.1016/j.ca nlet.2015.02.013

Napolitano MJ, Shain DH (2005) Quantitating adenylate nucleotides in diverse organisms. J Biochem Biophys Method 63:69-77. https://doi.org/10.1016/j.jbbm.2005.03.001

Perdosa J, Gravato C, Campos D et al. (2017) Investigating heritability of cadmium tolerance in Chironomus riparius natural populations: a physiological approach. Chemosphere 170:83-94. https://doi. org/10.1016/j.chemosphere.2016.12.008

Pyza E, Mak P, Kramarz P, Laskowski R (1997) Heat Shock Proteins (HSP70) as Biomarkers in Ecotoxicological Studies. Ecotoxicol Environ Saf 38:244-251

Richter C, Schweizer M, Cossarizza A, Franceschi C (1996) Control of apoptosis by the cellular ATP level. FEBS Lett 378:107-110

Rojas E, Lopez MC, Valverde M (1999) Single cell gel electrophoresis assay: methodology and applications. J Chromatogr B 722:225-254. https://doi.org/10.1016/S0378-4347(98)00313-2

Sandbichler AM, Höckner M (2016) Cadmium Protection Strategies-A Hidden Trade-Off? 17:1-22. https://doi.org/10.3390/ijms17010139

Sokolova I, Sokolov E, Ponnappa K (2005) Cadmium exposure affects mitochondrial bioenergetics and gene expression of key mitochondrial proteins in the eastern oyster Crassostrea virginica Gmelin (Bivalvia: Ostreidae). Aquat Toxicol 73:242-255

Woźniak K, Błasiak J (2002) Free radicals-mediated induction of oxidized DNA bases and DNA - Protein cross-links by nickel chloride. Mutat Res - Genet Toxicol Environ Mutagen 514:233-243. https://doi.org/10.1016/S1383-5718(01)00344-8

Zheng S, Henken B, Wietsma W et al. (2000) Development of bioassays and screening for resistance to beet armyworm (Spodoptera Exigua Hübner) in Allium cepa L. and its wild relatives. Euphytica 114:77-85. https://doi.org/10.1023/A:1004089424419 